\title{
HACIA UNA VISIÓN COMPREHENSIVA DEL NEXO ENTRE MIGRACION, DESARROLLO Y DERECHOS HUMANOS
}

ALEJANDRO I. CANALES*

\section{Resumen}

En este texto nos interesa contribuir, desde una perspectiva crítica, al análisis y entendimiento de los complejos vínculos entre el desarrollo, la migración internacional y los derechos humanos. En particular, se orienta a los sesgos de los sistemas de información, indicadores, instrumentos y categorías de análisis usadas actualmente, las cuales suelen reflejar los intereses y las problemáticas de la migración que surgen de la visión que se tiene de ella en los países de destino. En tal sentido, este documento tiene como objetivo promover el debate sobre la necesidad de generar un sistema de información que incluya un nuevo conjunto de indicadores estratégicos a través de los cuales se pueda analizar los vínculos entre la migración, el desarrollo y los derechos humanos; se trata de una perspectiva más integral y comprehensiva, que tome en cuenta los costos y beneficios para todas las partes involucradas, incluidos los migrantes.

Palabras clave: migración, desarrollo, derechos humanos, indicadores estratégicos, corredor México-Estados Unidos

* Profesor-investigador del Departamento de Estudios Regionales de la Universidad de Guadalajara. Dirección electrónica: acanales@cucea.udg.mx. 


\begin{abstract}
In this text we contribute to a critical perspective on analysis and understanding of the complex links between development, international migration and human rights. Our criticism is aimed at the biases of information systems, indicators and analytical categories currently used, which often reflect the interests and views of migration arising from the destination countries. In that sense, this paper aims to promote debate on the need to create an information system that includes a new set of strategic indicators, through which to analyze the links between migration, development and human rights. It is an integral and comprehensive perspective that takes into account the costs and benefits for all stakeholders, including migrants.
\end{abstract}

Keywords: migration, development, human rights, strategic indicators, US-Mexico Corridor 


\section{INTRODUCCIÓN}

$\mathrm{L}$ a migración internacional ha vuelto a ocupar los principales titulares de la agenda política y social; sin embargo, el discurso suele estar dominado por una perspectiva reduccionista y sesgada hacia los intereses de los principales países receptores en el norte: las causas estructurales y los impactos de la migración internacional en los países emisores y receptores suelen ignorarse; el papel de las remesas se sobreestima, los costos que la migración representa para los migrantes y sus familias quedan al margen, y el tema de los derechos humanos de los inmigrantes es soslayado y subordinado a los intereses de la política de seguridad nacional.

Desde una perspectiva crítica, se han desarrollado enfoques alternativos que no solamente cuestionan la validez empírica de estos argumentos, sino también sus fundamentos teóricos y políticos; en particular, se cuestiona el evidente reduccionismo y sesgo ideológico en la construcción del problema en torno a la relación migración-desarrollo (Delgado y Márquez, 2009; Canales, 2011).

Considerando los alcances de este debate, nuestra crítica se centra, en esta ocasión, en el hecho de que los sesgos en el enfoque dominante se deben, en cierta medida, a la manera en que se han construido los sistemas de información estadística, esto es, las categorías y unidades de análisis y observación utilizadas, así como los indicadores e instrumentos de medición, lo cuales no hacen sino reflejar los intereses y problemáticas que desde los países de destino se tiene de la migración contemporánea.

Este documento tiene como objetivo promover el debate sobre la necesidad de generar un sistema de información que incluya un nuevo conjunto de indicadores estratégicos, a través de los cuales se pueda analizar el vínculo entre migración, desarrollo y derechos humanos; se trata de una perspectiva integral, que toma en cuenta los costos y beneficios para todas las partes involucradas, incluidos los migrantes. 


\section{HACIA UNA EVALUACIÓN DE LOS VÍNCULOS ENTRE MIGRACIÓN, DESARROLLO $Y$ DERECHOS HUMANOS}

En un texto reciente presentado en el Foro Global de Migración y Desarrollo (FGMD), Delgado, Márquez y Puentes (2010) proponen un marco analítico y conceptual sobre el cual sustentar un enfoque comprehensivo de la relación entre migración, desarrollo y derechos humanos. Desde la misma perspectiva, en un documento complementario al anterior (Puentes et al., 2010), se identifican cuatro grandes limitaciones de la visión dominante, que reducen la capacidad de entendimiento de las causas y consecuencias de la migración internacional en la sociedad global contemporánea:

- Sobrevaloración de las remesas. Aunque se reconoce que no existe un consenso en torno al significado y magnitud de los efectos sociales e impactos económicos de las remesas (De Has, 2007), en la actualidad tiende a predominar una posición celebratoria de sus posibles efectos en las economías receptoras del tercer mundo. Da la impresión de que desde los organismos internacionales se estuviera impulsando un nuevo paradigma del desarrollo en nuestras sociedades, en el cual la migración y las remesas asumirían un papel preponderante, sustituyendo el que en anteriores esquemas y paradigmas del desarrollo habrían jugado el Estado y el mercado (Kapur, 2004).

- Balance fragmentado de los costos y beneficios de la migración. La sobrevaloración del impacto de las remesas lleva a soslayar e ignorar los costos sociales, económicos y demográficos de la migración en los países de origen; asimismo, en los países de destino, la inmigración internacional es vista como una cuestión social y política, lo cual invisibiliza el aporte de los inmigrantes a esas economías y sociedades, aporte no sólo en términos económicos, sino también demográficos, sociales y culturales (Canales, 2009; Delgado Wise y Márquez, 2007). Finalmente, suelen minusvalorarse los costos económicos, sociales y familiares que implica la migración forzada (por factores políticos o catástrofes ambientales, entre otros). 
- Distorsión de la cuestión de los derechos humanos. La invisibilidad de muchos de los costos y beneficios de la migración, de sus causas estructurales y del aporte de los inmigrantes redunda en una grave distorsión en el análisis y el diseño de políticas orientadas a la defensa y respeto de los derechos humanos y laborales. El debate suele centrarse en los temas económicos, a la vez que se consolida una visión que considera la migración internacional como parte de la agenda de seguridad nacional en los países de destino, todo lo cual ha redundado en propuestas y leyes que tienden a criminalizar la migración indocumentada (Martínez, 2008).

- Las causas de la migración han quedado fuera del debate actual. El debate y la reflexión sobre las causas estructurales de la migración ha quedado relegado a un segundo plano, cuando no simplemente olvidado. Así, por ejemplo, suelen apuntarse las condiciones de subdesarrollo y pobreza en los países de origen como las principales causas de la migración, pasando por alto, sin embargo, el papel que tienen en el desencadenamiento y causación de la inmigración las condiciones prevalecientes en los países de destino, especialmente las transformaciones en su estructura económica y laboral, así como la dinámica del cambio demográfico.

Lo anterior nos lleva a confirmar la necesidad de avanzar en una nueva perspectiva de análisis que, desde una visión global y comprehensiva, permita reconfigurar la agenda sobre la migración internacional, y que vaya más allá de la visión dominante que la ha reducido a una relación lineal entre remesas y desarrollo. Se trata de un enfoque que propone, en cambio, una visión multidimensional de la dinámica de la migración contemporánea y sus vínculos con el desarrollo y los derechos humanos.

Para ello, es necesario avanzar, junto con la reflexión conceptual sobre sus causas e impactos, en la configuración de un sistema de información orientado a proveer evidencia empírica y analítica a esta perspectiva crítica y comprehensiva de la migración. Al respecto, un primer paso corresponde a la identificación y el diseño de un sistema de indicadores estratégicos que puedan ser usados en diversos contextos y corredores migratorios. 
El presente documento avanza en esta dirección, presentando un análisis para el caso del corredor migratorio México-Estados Unidos, con base en un conjunto de indicadores estratégicos que nos permite analizar exhaustivamente las causas y los efectos de la migración para los dos países, así como para los migrantes y sus familias.

Antes de avanzar en la propuesta sobre un sistema de indicadores estratégicos, quisiéramos revisar brevemente algunas propuestas que se han popularizado recientemente: por una parte, el diseño y la elaboración de Perfiles Migratorios (PM) a partir de un conjunto de indicadores tradicionales (demográficos, laborales y sociales, entre otros); y por otra, el diseño de indicadores complejos sobre aspectos específicos de la migración, como la inclusión y derechos cívicos de los inmigrantes y el ampliamente conocido índice de desarrollo humano.

\section{DE LOS PERFILES MIGRATORIOS A UN SISTEMA DE INDICADORES ESTRATÉGICOS: EL PODER DE LA INFORMACION}

La importancia de la investigación, especialmente aquélla orientada a construir bases de datos confiables y el manejo de indicadores relevantes no es un tema nuevo: desde los años setenta, la Organización de las $\mathrm{Na}$ ciones Unidas (ONU) ha insistido en la necesidad de enriquecer y estandarizar las estadísticas sobre los flujos migratorios como base para el diseño de políticas públicas. En tal sentido, en los documentos de su División de Estadísticas se plantean recomendaciones muy concretas a los países miembros (onU, 1998). Por su parte, la necesidad de mejor información fue también una de las conclusiones de la Comisión Mundial sobre las Migraciones Internacionales en 2005 (CMMI, 2005). El informe Migrants Count ha sido otra aportación importante, con recomendaciones concretas a los gobiernos y a las agencias internacionales (Santo Tomas et al., 2009).

En este contexto, y casi simultáneamente con las conclusiones de la Comisión Mundial sobre Migración Internacional (сммI), la Comisión Europea (CE) anunció en 2005 una iniciativa sobre PM, justificada por la necesidad de contar con una caracterización detallada sobre la dinámica migratoria de los países como base para el diseño y la evaluación de nuevas políticas. Originalmente, los PM fueron concebidos 
como informes estadísticos «suficientemente completos pero concisos» para facilitar una comprensión rápida sobre la situación migratoria de un determinado país (FGMD, 2010). Para agilizar comparaciones, los PM se confeccionaban siguiendo lineamientos estrictos. Los primeros PM, elaborados quizá a partir de una visión tradicional y simplista de la migración, se circunscribían fundamentalmente a la recopilación y análisis de información económica y demográfica ya disponible en los archivos $\mathrm{y}$ censos nacionales.

Entre las interrogantes planteadas en esos primeros PM se priorizaba lo relacionado a la situación del mercado laboral, las tasas de desempleo, el balance entre oferta y demanda de trabajo, los potenciales problemas originados por falta de fuerza de trabajo en determinados sectores de la economía y las posibilidades de enfrentar esos déficits con fuerza de trabajo migrante. En el caso de los países de origen, los requerimientos de información se orientaron a la necesidad de contar con estimaciones y mediciones confiables del volumen de las remesas, así como de sus impactos. Es claro que estas preguntas respondían fundamentalmente a los intereses de los países receptores. Con el tiempo, el concepto de PM ha ido evolucionando para presentar una visión más integral de la situación migratoria de los países analizados.

En 2006, la Organización Internacional para las Migraciones (OIM) adoptó el concepto de PM y comenzó a apoyar, e incluso a coordinar la elaboración de PM en muchos países de acuerdo con lineamientos estandarizados y muy específicos dictados por la organización. Actualmente, existen PM para más de 70 naciones (Laczko, 2011). La oim los describió como una herramienta fundamental para alimentar los procesos de diseño de políticas públicas relacionadas con la migración internacional, y estableció que para que fueran efectivamente útiles, los PM deberían ser «propiedad de los gobiernos» y preparados por expertos gubernamentales con la asistencia de organizaciones internacionales. Por lo que antecede, la participación de la sociedad civil organizada en la preparación de esos PM ha sido débil, aunque las consultas se han abierto en los últimos PM elaborados.

Sin negar el valor de la información compilada en los PM, sobre todo en determinados países donde ese trabajo de recopilación y análisis 
nunca se había realizado, tanto su conceptualización original como la manera de interpretar y presentar los datos demográficos y económicos los colocan dentro de las herramientas que difícilmente mueven el debate hacia canales diferentes. En este sentido, es interesante destacar que incluso algunos expertos nacionales encargados de implementar los PM en sus países han comentado que la información recabada, aunque necesaria, no es suficiente para diseñar políticas más efectivas y justas (Manzelli, 2011).

A seis años de las recomendaciones de la CMMI y de la iniciativa de la CE, los PM vuelven a ser colocados en la agenda dentro del proceso del FGMD por los organizadores del V Foro en Ginebra en 2011 (FGMD, 2011). Como se espera una participación activa de la sociedad civil en dicha reunión, se presenta una oportunidad única para retomar las conclusiones de la Acción Global de los Pueblos (AGP) en el Foro anterior en México y profundizar en un proceso de investigación, análisis y propuestas donde la sociedad civil y la academia colaboren y participen efectivamente hacia el Diálogo de Alto Nivel de la onU de 2013.

Ahora bien, aunque se trata de un esfuerzo metodológico loable y, en no pocos casos, bien logrado, desde nuestra perspectiva creemos que la principal limitación de la propuesta de los PM es que se sustentan en los enfoques tradicionales de la migración y el desarrollo, los cuales suelen desvincular las condiciones, causas y contribuciones de la migración en los lugares de origen de las condiciones, causas y contribuciones en los lugares de destino. Asimismo, se centran fundamentalmente en la caracterización de los migrantes, dejando en un segundo plano la caracterización y el análisis de la migración como un proceso social de múltiples dimensiones.

Además de los PM, existen otros antecedentes, indicadores complejos y plataformas de implementación, de los cuales se pueden extraer lecciones interesantes. En general, se trata de la construcción de índices complejos que incluyen la medición de varias dimensiones del fenómeno migratorio; en comparación con los PM, estos índices tienen un carácter más amplio y global. Podemos citar tres ejemplos de índices complejos: 
- El Índice Europeo de Inclusión Cívica y Ciudadanía (eCCII, por sus siglas en inglés), que estima y compara las condiciones de inclusión de los migrantes en las sociedades de la UE. Es un índice compuesto que integra un número muy amplio de indicadores de inclusión social entre los que se destacan el acceso a mercados laborales, la reunificación familiar, la obtención de residencia y naturalización y las políticas antidiscriminatorias (Citron y Gowan, 2004).

- El Índice de Políticas de Integración de Migrantes (MIPEx, por sus siglas en inglés), diseñado para comparar las políticas de integración en Europa, Estados Unidos y Canadá (MPG, 2011). El MIPEX es un esquema multidimensional con 148 indicadores agrupados en siete áreas de políticas públicas que se integra para presentar el estado de la situación sobre oportunidades de integración y participación en la sociedad de los países receptores. Su diseño permite comparaciones entre países y estudios longitudinales.

- El Índice de Desarrollo Humano (IDH) para Migrantes Internos, diseñado para analizar las diferencias en el IDH entre residentes y migrantes internos, lo que permite comparaciones entre países y entre áreas urbanas y rurales (Harttgen y Klases, 2009).

No obstante los avances, los índices complejos también presentan una limitación metodológica: la unidad de análisis es un país determinado, de origen o destino, lo cual reduce significativamente la visión global del fenómeno migratorio contemporáneo.

En nuestro caso, partimos de una perspectiva diferente, que busca el diseño de un marco analítico y conceptual que ofrezca una visión integral y comprehensiva del fenómeno migratorio, así como sus vínculos con los procesos de desarrollo y la situación de los derechos humanos de los actores involucrados. Por lo mismo, creemos que es necesario partir también de una propuesta metodológica diferente que permita diseñar un sistema de información e indicadores estratégicos que recojan y den cuenta de la complejidad del fenómeno, así como de sus múltiples dimensiones. 
Considerando lo anterior, nuestra tesis es que, hoy más que nunca, la unidad de análisis más apropiada para sustentar una visión comprehensiva de la migración es la de corredor migratorio, una categoría que permite incluir en un mismo marco analítico las condiciones estructurales de los países de origen y destino, así como las características de los migrantes, sus familias y comunidades, todo ello junto con las características y la dinámica del proceso migratorio en sí mismo.

Se trata, sin duda, de un desafío metodológico que no es menor, pues implica el diseño de indicadores estratégicos que a la vez que dan cuenta de aspectos específicos del proceso migratorio (PM, dinámica de la migración como un proceso social, condiciones estructurales en origen y destino, impactos y contribuciones que van más allá del clásico enfoque de evaluación de costos y beneficios, entre otros), debe establecer las dimensiones y los niveles metodológicos que permitan una visión integrada y articulada de todos ellos. Esto es lo que intentaremos avanzar en las siguientes secciones, ofreciendo, primero, un marco metodológico para el diseño de estos indicadores estratégicos y, posteriormente, un ejemplo concreto de análisis con base en algunos de ellos, aplicados para el caso del corredor migratorio México-Estados Unidos.

PROPUESTA DE INDICADORES ESTRATÉGICOS: DESAFIOS CONCEPTUALES Y METODOLOGICOS

Los enfoques dominantes en el debate sobre la relación entre migración y desarrollo suelen mencionar un escenario win-win-win, en el cual todas las partes involucradas resultarían beneficiadas. Sin embargo, la realidad dista mucho de esta situación ideal: en los países de origen hay una completa ausencia de políticas de desarrollo que generen empleo y medios de subsistencia adecuados para toda la población; por su parte, las políticas migratorias de los países receptores plantean la criminalización de los migrantes, a la vez que permiten su sobreexplotación laboral. Lo anterior deriva en la perpetuación de un círculo vicioso de pobreza, marginación y discriminación en contra de los migrantes en ambos extremos de casi todos los corredores migratorios. 
Confrontar estos enfoques hegemónicos, implica una triple tarea. Primero, desarrollar marcos conceptuales y analíticos que ofrezcan una visión más amplia y comprehensiva del fenómeno; segundo, diseñar y proponer sistemas de información e indicadores estratégicos que provean elementos empíricos necesarios para sustentar estos enfoques comprehensivos; y tercero, diseñar programas y políticas en materias de migración, desarrollo y defensa de los derechos humanos que recojan el carácter multifacético y heterogéneo de esta cuestión social y política.

La necesidad de un sistema de información e indicadores estratégicos, como el propuesto en este documento, surge como respuesta a la perspectiva dominante en el análisis de la migración internacional que, desde un enfoque reduccionista y simplista, ha conducido al diseño de políticas y programas no solamente inadecuados, sino que además exacerban las tensiones y soslayan el abordaje de las causas y consecuencias fundamentales del problema. En resumen, un sistema de información alternativo debería facilitar el diálogo objetivo sobre los derechos de la migración, el desarrollo y los derechos humanos en países emisores y receptores, diálogo que debiera tener como actor central a las organizaciones de migrantes, así como otros actores involucrados.

$\mathrm{Al}$ respecto, los objetivos específicos de un sistema de información como el aquí propuesto, serían los siguientes:

- Llevar el debate más allá de las visiones reduccionistas de la migración, a la vez que se llenan los vacíos y distorsiones en la información y conocimiento de los vínculos entre desarrollo, migración y derechos humanos.

- Permitir una visión integral y balanceada de causas, costos y beneficios de la migración para todos los países y actores sociales involucrados.

- Mostrar los diversos impactos de la migración en países emisores y receptores y en los propios migrantes y sus familias.

- Facilitar el seguimiento y monitoreo de los posibles impactos derivados de las políticas migratorias implementadas en los países emisores y receptores.

- Servir como una herramienta para estudios de evaluación y vigilancia sobre políticas de migración, desarrollo y derechos humanos 
que permita la comparación de costos y beneficios de la migración a través del tiempo, y la identificación de oportunidades para corregir políticas y programas.

Para lograr estos objetivos, el enfoque analítico debe ser integral y comprehensivo, incluyendo una gama mucho más amplia de indicadores que los que son usados habitualmente. A diferencia de los marcos metodológicos tradicionales, que se basan en indicadores que analizan en forma aislada cada una de estas dimensiones, nuestro enfoque busca pasar a un análisis de sus vinculaciones y dinámicas interdependientes.

La construcción de un sistema de información e indicadores estratégicos es, sin duda, un proceso complejo que implica desafíos conceptuales y metodológicos. Por lo pronto, un modelo como este debe ser capaz de trabajar simultáneamente en diferentes niveles de análisis y con las diferentes dimensiones que conlleva el proceso migratorio, lo que significa abordar de manera sistemática tanto las causas como los impactos para cada situación concreta, y para cada corredor migratorio en particular.

$\mathrm{Al}$ respecto, como hemos planteado, consideramos que la unidad de análisis por excelencia, la que mejor permite el diseño de un enfoque como el propuesto, es el corredor migratorio, a través del cual podemos ver en forma integrada las condiciones prevalecientes en los países de origen y destino, junto con la dinámica del proceso migratorio y los perfiles y características de los migrantes y sus familias.

En este sentido, nuestra propuesta para el diseño de un sistema de indicadores estratégicos identifica cuatro grandes dimensiones a través de las cuales se pueden observar y analizar los múltiples vínculos entre migración, desarrollo y derechos humanos en cada corredor migratorio. Todas las dimensiones se ilustran en la figura 1.

Nuestra perspectiva es que en cada corredor migratorio se configura un sistema de relaciones que vinculan cada una de estas dimensiones y niveles de análisis. Así, por ejemplo, la situación de los migrantes está determinada en gran medida por las condiciones estructurales que, desde los lugares de origen y destino, promueven e impulsan sus desplazamientos. Asimismo, los impactos y consecuencias de la migración en 
los lugares de origen y destino no son ajenos a las causas estructurales que desencadena la migración, como tampoco a las formas que asume el proceso y los sujetos que involucra.

FIGURA 1

Dimensiones del modelo de indicadores estratégicos

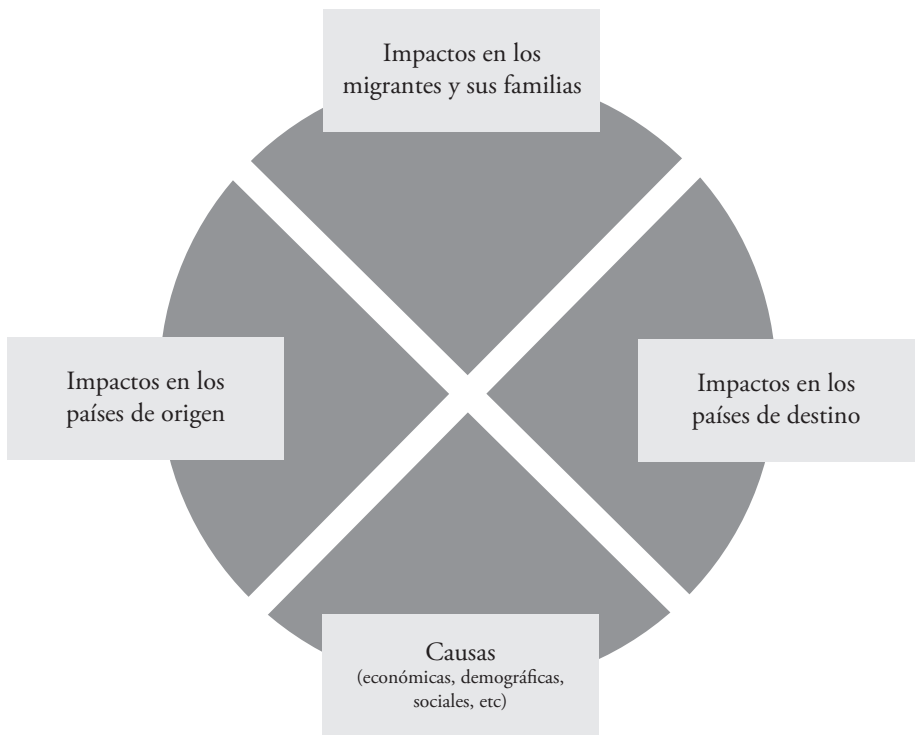

Identificadas estas cuatro dimensiones relevantes, el desafío se traslada ahora al diseño de los indicadores estratégicos para cada una de ellas. Se trata no de simples indicadores que describan una realidad, sino de indicadores que permitan visualizar también los vínculos entre estas diferentes dimensiones. Así, por ejemplo, en términos de los impactos, el análisis de los indicadores debe incluir no solamente los costos y beneficios para cada país, sino que debe llevarnos también a ver las relaciones entre ellos, de modo que sea posible visualizar cómo los costos para uno pueden representar los beneficios para otros.

Asimismo, y considerando que nuestro objetivo es profundizar en el nexo entre desarrollo, migración y derechos humanos, se debería definir un mínimo de indicadores que den cuenta no solamente de la distribución del ingreso en cada país o de la situación de pobreza y subdesarrollo, 
sino de indicadores sobre las condiciones de desigualdad económica y asimetrías productivas entre países de origen y destino, así como también de las asimetrías y complementariedades económicas, laborales y demográficas. Junto a estos, se necesitan indicadores que informen, entre otros aspectos, de las transformaciones en la estructura social y económica, el desarrollo humano y el respeto a los derechos humanos.

Para ilustrar el potencial analítico de este modelo de indicadores estratégicos, presentamos en las siguientes secciones una evaluación de la situación en el corredor migratorio entre México y Estados Unidos. Considerando las restricciones de espacio, hemos debido centrarnos en un número reducido de indicadores. Sin embargo, como veremos, el análisis nos muestra una realidad que es, a todas luces, mucho más compleja que la descrita en los enfoques tradicionales, especialmente la referida a los PM y a otros indicadores demográficos. Por lo pronto, resulta evidente la importancia de las desigualdades económicas y las asimetrías productivas en el desencadenamiento de la migración.

Los indicadores dejan al descubierto las grandes contribuciones de los inmigrantes mexicanos en la sociedad estadounidense, mismas que son a menudos soslayadas por el discurso actual que tiende a criminalizar a los inmigrantes y a colocar la migración como un tema de las agendas de seguridad nacional, y no dentro de la agenda social, económica o demográfica.

\section{PROPUESTA DE INDICADORES ESTRATÉGICOS A PARTIR DE LA EXPERIENCIA DEL CORREDOR MEXICO-ESTADOS UNIDOS}

El corredor migratorio México-Estados Unidos configura un espacio privilegiado de aplicación del enfoque comprehensivo sobre la relación migración, desarrollo y derechos humanos. A continuación se presenta, a manera de ilustración, un análisis con base en algunos indicadores estratégicos, lo cual nos permite mostrar el potencial analítico del enfoque propuesto.

La presentación de los indicadores estratégicos sigue el esquema propuesto, basado en cuatro grandes dimensiones, a saber, las causas socio-estructurales de la migración, las contribuciones de los inmigrantes 
en la economía y demografía de Estados Unidos, los costos y beneficios de la emigración para México y los impactos para los migrantes.

\section{Causas de la migración}

Últimamente, el análisis de las causas de la migración ha sido soslayado y simplificado. Esto ha llevado a planteamientos simplistas y superficiales, tales como el suponer que las condiciones de subdesarrollo y pobreza que prevalecen en los países de origen son los factores estructurales que promueven la migración. La superficialidad de afirmaciones de este tipo queda manifiesta cuando vemos que no es solamente la falta de desarrollo lo que genera la emigración masiva, sino también, y fundamentalmente, el estilo de desarrollo, en particular, la persistencia en el tiempo de procesos de desarrollo desigual que se manifiestan en el incremento de las asimetrías económicas, sociales y productivas entre los países de origen y destino de la migración.

En tal sentido, sostenemos que las asimetrías socioeconómicas que se presentan entre los países que configuran los diversos corredores migratorios están estrechamente asociadas a la dinámica migratoria. Al respecto, el caso del corredor migratorio México-Estados Unidos ilustra claramente esta tesis.

Un indicador que ilustra esta dimensión es la relación inversa que se establece entre la productividad relativa y la migración entre ambos países. En la siguiente gráfica se aprecia que, entre 1995 y 2009, la productividad relativa de la manufactura en México respecto a la de Estados Unidos exhibe una tendencia sistemáticamente decreciente; en tanto que la emigración, una trayectoria ascendente. No se trata de un fenómeno coyuntural, sino de una tendencia estructural de largo plazo que indica una posible relación causal.

En efecto, en los últimos 15 años, la integración económica promovida por el Tratado de Libre Comercio de América del Norte (TLCAN) no ha derivado en una convergencia productiva entre ambos países (como supusieron los impulsores de ese acuerdo comercial), sino, por el contrario, en una creciente asimetría y desigualdad productiva que se refleja en estos dos fenómenos que hemos destacado; por un lado, 
en una pérdida sistemática de productividad relativa en el sector manufacturero mexicano y, por el otro, en un sistemático incremento de la tasa de emigración mexicana a Estados Unidos, al grado que actualmente hay más de 12 millones de mexicanos residiendo en ese país (ver gráfica 2).

Asociado a las asimetrías en el ámbito productivo, se producen tendencias igualmente contrapuestas en los mercados laborales de los países emisores y receptores. En el caso de México y Estados Unidos, por ejemplo, se aprecia un superávit en la oferta laboral y un déficit de fuerza de trabajo. En el caso de México, entre 2000 y 2008 , el empleo formal creció en apenas 2 millones de personas; sin embargo, en el mismo periodo, el empleo informal se expandió en más de 3.2 millones, a los que habría que sumar el incremento de los trabajadores mexicanos residentes en Estados Unidos, los cuales se incrementaron en otros 3 millones. Esto significa que, de no mediar la emigración a Estados Unidos, el mercado laboral mexicano habría enfrentado un déficit de ocupaciones o su equivalente, un superávit de trabajadores del orden de los 6.2 millones de personas, es decir, un déficit de 770 mil empleos cada año (ver gráfica 2).

GRÁFICA 1

Índice de productividad relativa de México vis-à-vis Estados Unidos $(2005=100)$ y tasa de emigración a Estados Unidos (\%)

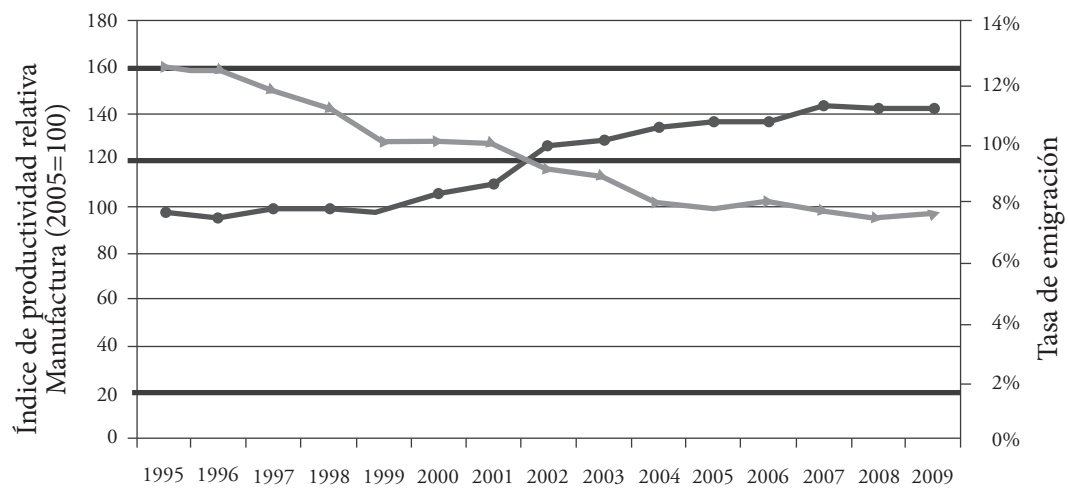

Fuente: Índice de Productividad Relativa: estimación basada en datos de oECD Statistic, 1995-2009. Tasa de emigración: estimación basada en datos de Current Population Survey, march supplement, 1995 a 2009; datos de la población mexicana tomados de Conapo: www.conapo.gob.mx. 
GRÁFICA 2

Crecimiento de ocupación y mano de obra en México y Estados Unidos, 2000-2008 (millones de personas)

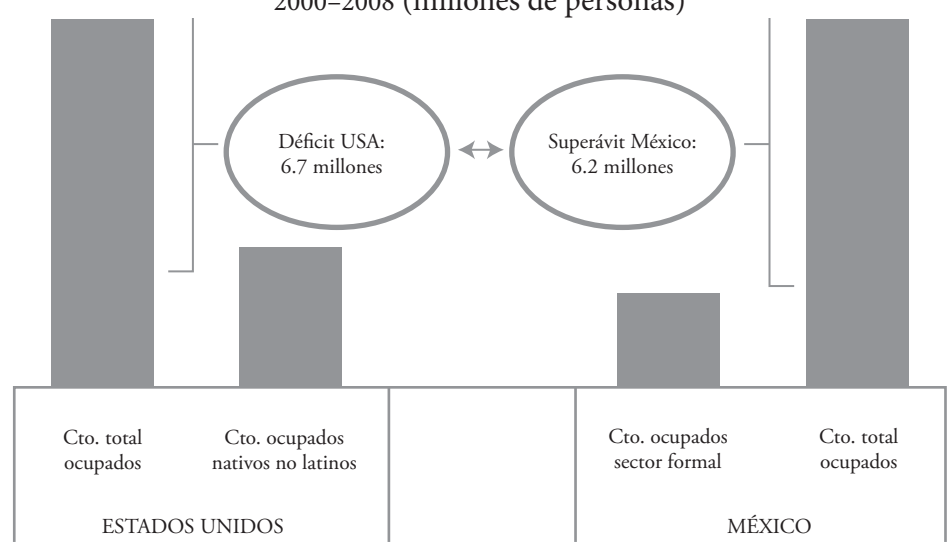

Fuente: Elaboración propia con base en Cepalstat, Estadísticas de empleo de CEPAL, y Current Population Survey, march supplement, 2000-2008.

Por el contrario, en el mercado laboral estadounidense, asistimos a la tendencia opuesta. En este caso, el crecimiento del empleo entre 2000 y 2008, fue de 10.3 millones de puestos de trabajo; sin embargo, solamente el $35 \%$ de este crecimiento correspondió a trabajadores nativos no latinos o, lo que es lo mismo, el $65 \%$ restante debió ser cubierto con mano de obra extranjera o por nativos de origen latinoamericano. Esto nos da una aproximación del nivel del déficit de mano de obra que experimenta actualmente Estados Unidos y, por tanto, de su imperiosa necesidad de recurrir a mano de obra migrante para cubrir las ocupaciones que la dinámica económica está generando cada año.

\section{Contribuciones de la migración mexicana} a la demografía y economía de Estados Unidos

Al focalizar las causas de la migración en las condiciones de subdesarrollo prevalecientes en los países de origen, los enfoques dominantes suelen invisibilizar el aporte de los inmigrantes a las sociedades receptoras, aporte no solamente en términos económicos, sino también demográficos, sociales y culturales (Delgado Wise y Márquez, 2007). En tal 
sentido, presentamos a continuación un set de indicadores estratégicos que nos permiten estimar el nivel de aporte de la migración mexicana a la sociedad estadounidense.

\section{Contribuciones demográficas}

Considerando tanto su volumen absoluto como su composición etaria, es indudable que la inmigración mexicana tiene importantes impactos en la dinámica demográfica en Estados Unidos. En particular, podemos señalar dos aspectos en los cuales se da esta contribución: por un lado, en términos de su aporte al crecimiento demográfico, en forma directa y a través de su descendencia; por otro lado, en términos de los cambios en la composición étnica de la población de ese país.

En relación al primer punto, entre 2000 y 2008 , la población de Estados Unidos se incrementó en 25 millones de personas. Por grupos étnicos, vemos que la población de origen mexicano es la que experimentó el mayor crecimiento absoluto; de hecho, en conjunto, la población de origen mexicano contribuyó con el 35\% del crecimiento demográfico de Estados Unidos de los últimos ocho años. Por el contrario, la población angloamericana, a pesar de constituir el principal grupo étnico del país, con una población de más de 190 millones de personas, apenas contribuyó al crecimiento de la población con 3.6 millones de personas, que representó solamente el $14 \%$ del crecimiento total (ver gráfica 3 ).

GRÁFICA 3 Estados Unidos, 2000-2008. Composición y tasas de crecimiento demográfico según principales grupos étnicos y migratorios
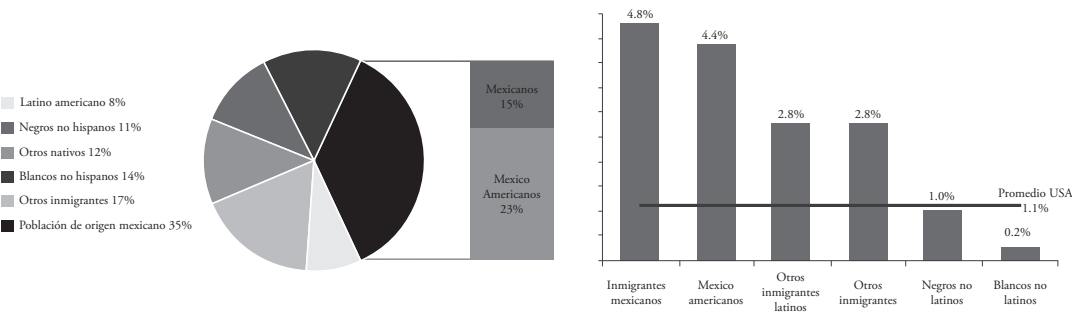

Fuente: Estimaciones propias con base en Current Population Survey, march supplement, 2000 y 2008. 
En términos de la tasa de crecimiento, las diferencias son aún más evidentes y abismales. Mientras la población blanca no latina apenas creció a una tasa de $0.2 \%$ anual promedio, los inmigrantes mexicanos lo hicieron a una tasa de $4.8 \%$ y los mexicoamericanos a una de $4.4 \%$ anual promedio. Esto es, los migrantes mexicanos y los mexicoamericanos crecieron a un ritmo que es más de $20 \%$ superior al de la población blanca no latina.

Estas diferencias en el crecimiento demográfico son todavía más claras si se desagrega por grandes grupos de edad; en efecto, como se observa en la siguiente gráfica, mientras la población blanca no latina y, en menor medida, los negros no latinos, tienden al envejecimiento, esto es, a un incremento de la población en edades mayores, y a la reducción de niños y jóvenes, la población de origen latino (inmigrantes y nativos) experimenta el proceso inverso, esto es, un incremento de población infantil y adultos jóvenes (Canales, 2009).

Estados Unidos, 2000-2008. Crecimiento demográfico de principales grupos étnicos migratorios según grandes grupos de edad (millones de personas)

POBLACIÓN 0-14 AÑOS

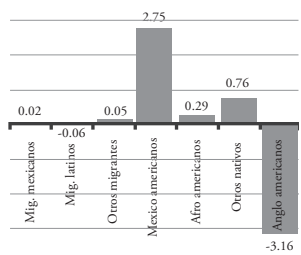

POBLACIÓN 15-49 AŃOS

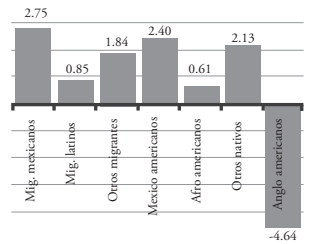

POBLACIÓN $50+$ AÑOS

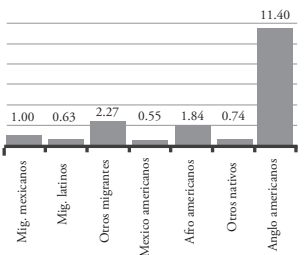

Fuente: Estimaciones propias con base en Current Population Survey, march supplement, años 2000 y 2008.

Esta dinámica diferenciada de crecimiento demográfico, según estratos de edad, expresa el diferente patrón de reproducción demográfica de cada grupo étnico. Mientras los angloamericanos se encuentran en pleno proceso de envejecimiento demográfico, la población de origen mexicano presenta una dinámica opuesta, de gran crecimiento y predominio de población en edades jóvenes y reproductivas.

Este proceso de complementación demográfica está teniendo, además, importantes repercusiones en la composición étnica de la población estadounidense. De hecho, no se trata solamente de un proceso de complementación etaria pura y simplemente, sino que, de seguir 
estas tendencias a mediano plazo, estaríamos asistiendo a un sustancial cambio en la composición étnica y migratoria de la población estadounidense que podría derivar en un eventual reemplazo demográfico, esto es, un virtual reemplazo de población blanca no latina por población de origen mexicano y latinoamericano.

En efecto, como se observa en la siguiente gráfica, las tendencias que ya se observan en las últimas cuatro décadas, y que se proyectan para las próximas décadas, permiten tener una adecuada aproximación de los alcances que tienen las actuales dinámicas demográficas de los diferentes grupos étnicos en Estados Unidos.

GRÁFICA 5

Estados Unidos, 1970, 2010 y 2050.

Población según grandes grupos étnicos y migratorios (millones de personas)

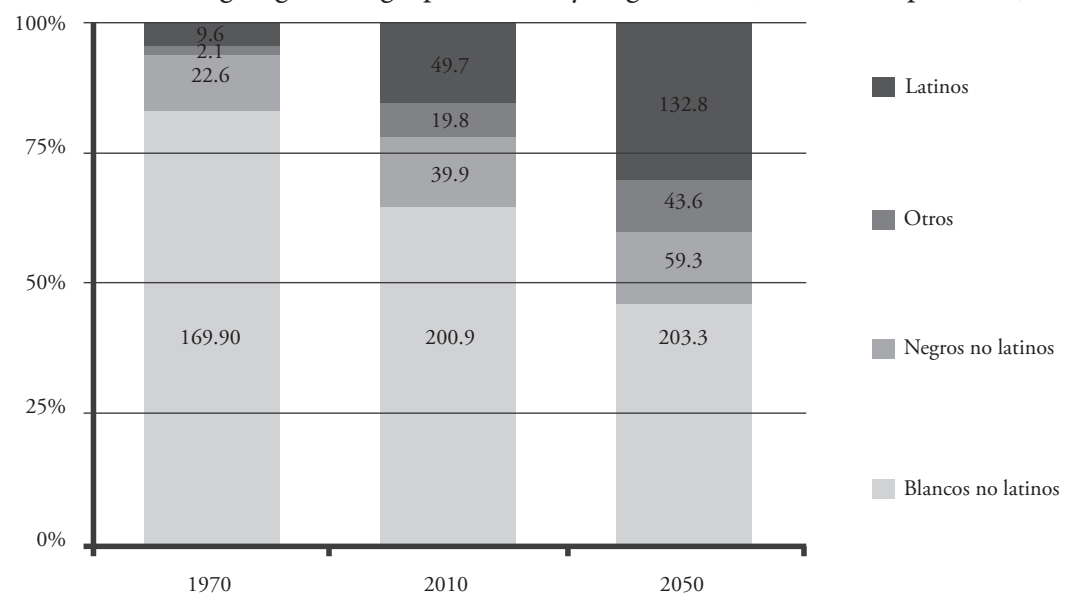

Fuente: 1970: us Census Bureau, Censos de población; y 2010-2050: Population division/ Projections of the Population by Sex, Race, and Hispanic Origin for the United States: 2010 to 2050 (NP2008- T4).

El envejecimiento de la población blanca no latina afecta directamente su capacidad de reproducción demográfica. Si hacia 1970 era innegable la supremacía de los blancos no latinos, que representaban el 83\% del total de la población estadounidense. Hacia 2010, esta supremacía se habría reducido, de modo que este grupo étnico aportaba menos del $65 \%$ de la población total. Asimismo, de continuar con estas tendencias, se estima que para el año 2050, los blancos no latinos representen solamente el $46.3 \%$ de la población total, dejando de ser, por lo tanto, una mayoría absoluta. 
Por el contrario, los altos volúmenes de inmigración mexicana y latinoamericana, junto a su elevada fecundidad, plantean el escenario inverso, esto es, de un gran crecimiento demográfico, especialmente de población joven y en edades reproductivas. En efecto, si en 1970 representaban menos del 5\% de la población total, para 2010 ya alcanzaban el 16\% de la población estadounidense, y se proyecta que para 2050 este grupo étnico represente algo más del 30\% del total de la población. Esta dinámica de crecimiento llevaría a este grupo étnico a dejar de ser una simple minoría étnica, para convertirse en un grupo con la fuerza demográfica suficiente, que la ubicaría como la segunda mayoría relativa, cuestionando directamente la tradicional primacía demográfica de la población blanca no latina.

De tal forma, estas diferentes y opuestas dinámicas demográficas derivarían en un proceso de reemplazo étnico y demográfico, el cual ya se manifiesta en el caso de la población de algunos estados, como California y Texas (dos de los estados más poblados de Estados Unidos), así como en las ciudades de Los Ángeles, Miami y Houston, donde el volumen de la población de origen latino ya es igual o superior al de la población blanca no latina (Canales, 2011).

\section{Contribuciones al crecimiento económico}

Aunque suele reconocerse que los inmigrantes son un componente significativo de la fuerza de trabajo ocupada, especialmente en sectores y ocupaciones específicas, hasta ahora hay escasos estudios que muestren el aporte que, como fuerza laboral, realizan los inmigrantes a la generación del Producto Interno Bruto (Рів) de los países de destino y, por ese medio, a la dinámica económica de los países receptores. Con base en la estimación del valor del PIB generado por la fuerza de trabajo según su condición migratoria, podemos calcular, entonces, el aporte que los inmigrantes mexicanos han hecho al crecimiento económico reciente de Estados Unidos. ${ }^{1}$

${ }^{1}$ Nos basamos en un modelo que ya hemos presentado otras ocasiones (Canales, 2009 y 2011). 
Como se observa en la siguiente gráfica, el crecimiento del PIB de Estados Unidos en la segunda mitad de los noventa se sustentaba fundamentalmente en el aporte que hacían los trabajadores nativos blancos no hispanos; en conjunto, ellos contribuían con el 54.4\% del crecimiento del PIB. Entre 2000 y 2007, en cambio, son las minorías étnicas y migratorias las que generan en conjunto el mayor aporte al crecimiento económico, con casi el 54\%.

\section{GRÁFICO 6}

Estados Unidos, 1995-2000 y 2000-2007.

Contribución al crecimiento del PIB según origen étnico de los trabajadores 1995-2000 2000-2007
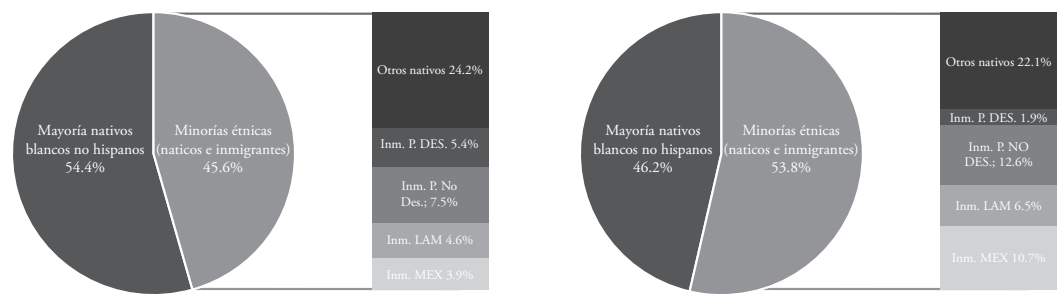

Fuente: Estimaciones propias con base en datos de BEA, Gross Domestic Product by Industry Accounts 1995-2007 y Current Population Survey, march supplement, 1995 a 2008.

En estas minorías, los inmigrantes provenientes de países en desarrollo son los que manifiestan el mejor desempeño económico. Si a fines de los años noventa aportaban únicamente el 16\% del crecimiento del PIB, entre 2000 y 2007 aportaron casi el 30\%. Dentro de esta minoría, cabe destacar el papel de los inmigrantes mexicanos, quienes pasan de contribuir con menos del 4\% del crecimiento del PIB a fines de los años noventa, a aportar casi el 11\% del crecimiento entre 2000 y 2007. Estos datos ilustran el cambio en el peso relativo de cada grupo étnico en la dinámica económica de Estados Unidos. Si tradicionalmente el crecimiento de esa economía se sustentaba en la fuerza de trabajo nativa blanca no hispana, es evidente que en las últimas décadas el crecimiento económico empieza a sustentarse cada vez más en las minorías étnicas y migratorias; es un cambio que tiene grandes implicaciones, más aún si se considera que se trata no solamente de la principal economía del mundo, sino, además, de una economía que necesita la generación de los excedentes económicos necesarios para mantener su liderazgo económico, político y militar a nivel mundial. 
Impactos en países de origen

El enfoque hegemónico sobre migración y desarrollo está tan enfocado en enaltecer los beneficios de la migración para los países emisores, restándole importancia a los costos de todo tipo que la emigración representa para estos países y economías. Considerando lo anterior, en este apartado queremos presentar algunos indicadores que permiten medir, en parte, el costo que representa para los países de origen la emigración de importantes contingentes de su población. Presentamos, en primer lugar, una evaluación de los impactos económicos de las remesas; en segundo lugar, estimamos el costo demográfico y laboral que está representando actualmente la emigración de población en edades jóvenes; por último, presentamos una estimación de los costos que la emigración representa en relación a la formación educativa y reproducción social de estos emigrantes.

\section{Impactos económicos}

Cuando se analiza el impacto económico de la migración, el énfasis es puesto generalmente en el flujo de remesas y su papel en diversos ámbitos de la economía mexicana. Para los países de alta migración, como México, suele señalarse que las remesas representan un aporte económico en, al menos, tres ámbitos: contribución al crecimiento del PIB, reducción de la pobreza y estabilidad macroeconómica. Sin embargo, los datos para el caso mexicano no parecen concordar con esta visión optimista de las remesas.

Por un lado, la contribución al crecimiento a través de sus efectos multiplicadores es bastante reducido y muy lejano a las expectativas que se tienen de ellas. En efecto, de acuerdo con los datos oficiales que ofrece el Banco de México, entre 2001 y 2010, el incremento anual de las remesas fue algo superior a los mil 100 millones de dólares (ver tabla 1). Se trata de un crecimiento significativo que representa, en promedio, una tasa del orden del 13\% anual. 
TABLA 1

Indicadores del impacto económico de las remesas en México, 2001-2010

\begin{tabular}{lr}
\hline CONTRIBUCIÓN DE LAS REMESAS AL CRECIMIENTO DEL PIB & $2,3 \%$ \\
\hline Remesas como proporción del PIB (2001-2010) & $13,1 \%$ \\
Crecimiento anual de las remesas & $4,2 \%$ \\
Crecimiento del PIB por efectos multiplicadores de las remesas (acumulado) & $3,801 \%$ \\
Crecimiento de la migración 2001-2010 (millones de personas) & $3,9 \%$ \\
\hline Proporción de la migración de la población Mexicana & $5,7 \%$ \\
\hline CONTRIBUCIÓN DE LAS REMESAS A LA REDUCCIÓN DE LA POBREZA Y DESIGUALDAD & $36 \%$ \\
\hline Hogares perceptores de remesas & $20,0 \%$ \\
Remesas como proporción del ingreso de los hogares perceptores & $1,3 \%$ \\
Porcentaje de hogares que reciben remesas que superan la pobreza & $1,3 \%$ \\
Impacto de las remesas en reducción de la pobreza & $8,0 \%$ \\
Impacto de las remesas en reducción de la desigualdad (Gini) & $62,0 \%$ \\
\hline CONTRIBUCIÓN DE LAS REMESAS A ESTABILIDAD MACROECONÓMICA Y EQUILIBRIOS EXTERNOS & $80,0 \%$ \\
\hline Remesas como proporción de las exportaciones totales & \\
Remesas como proporción de exportaciones petroleras & \\
Remesas como proporción de la inversión extranjera directa & \\
\hline
\end{tabular}

Fuente: Estimaciones propias con base en datos económicos del Banco de México, www.banxico.org.mx.

Sin embargo, a pesar de su explosivo crecimiento, las remesas han tenido, históricamente, una muy reducida contribución en la dinámica económica de México. Con base en sus efectos multiplicadores, estimamos que las remesas habrían contribuido a que el PIB mexicano se hubiera incrementado en apenas un $4.2 \%$ en todo el periodo, lo que equivale a un crecimiento de solamente $4.6 \%$ anual promedio.

Se trata de un cifra muy reducida, más aún si se compara con el gran esfuerzo migratorio que ella presupone. Entre 2001 y 2010 la población mexicana residente en Estados Unidos se incrementó prácticamente en 3.8 millones de personas, lo que representaría el 3.9\% de la población mexicana, de tal forma, podemos concluir que para generar un crecimiento de apenas un $4.2 \%$ del PIB, fue necesario que emigrara el 3.9\% de la población. Los datos son elocuentes y nos permiten avanzar una tesis más general: ningún modelo de crecimiento económico de un país es viable si se sustenta en la emigración masiva de su población; esa es una contradicción obvia, pero, por lo mismo, suele callarse y, por callada, suele olvidarse.

En relación con los logros en la reducción de la pobreza, la situación no es muy diferente. De acuerdo a estimaciones basadas en los datos que ofrece la Encuesta Nacional de Ingresos y Gastos de los Hogares, se concluye que entre 2000 y 2008 las remesas apenas habrían contribuido a 
reducir en 1.3\% el nivel de pobreza prevaleciente en México; ello se debe a que menos del $6 \%$ de los hogares mexicanos son perceptores de remesas, y que, de ellos, solamente en 1 de cada 5 las remesas constituyen un flujo de ingresos que les permite superar la línea de pobreza (Canales, 2008). Similar impacto se da si, en vez de considerar el nivel de pobreza, estimamos el impacto de las remesas en la reducción de la desigualdad en la distribución del ingreso. En este caso, las remesas apenas impactan en un $1.3 \%$ el valor del índice de Gini.

Por último, a nivel macroeconómico, las remesas sí parecen representar un flujo que ofrece relativa estabilidad monetaria; por un lado, representan un flujo continuo, periódico y estable, menos sensible a los vaivenes coyunturales de la economía financiera internacional, como la Inversión Extranjera Directa (IED) (Canales y Montiel, 2004). Sin embargo, entre 2001 y 2010, las remesas apenas representaron el $8 \%$ del volumen de las exportaciones totales. De esta forma, si bien las remesas constituyen un flujo de no poca importancia, resulta evidente que la estabilidad macroeconómica externa sigue descansando en las exportaciones, tanto petroleras como no tradicionales.

\section{Exportación del bono demográfico}

En México y en los demás países de América Latina, se asiste actualmente a la última fase de su transición demográfica, la cual se caracterizaría por el incremento, tanto en términos absolutos como relativos, de la población en edades activas ( 15 a 64 años). Esta dinámica se complementa con una reducción de la población infantil (menores de 15 años), que se iniciara algunos lustros atrás a partir del descenso de la fecundidad. Asimismo, si bien la población adulta mayor (de 65 años o más) comienza a experimentar un incremento en su volumen, este se mantiene aún en bajos montos demográficos, estando muy distante de la dinámica de crecimiento de la población en edades activas.

Esta combinación de tendencias demográficas provoca una coyuntura histórica única; desde hace algunos lustros y en las próximas décadas, la carga que representa la población inactiva será muy inferior con relación a la de otras coyunturas históricas, es por ello que a esta peculiar 
situación se la ha denominado «bono demográfico», ya que se quiere enfatizar la favorable situación, en términos de relaciones de dependencia y carga económica, que implica esta reducción de la población en edades inactivas (Conapo, 2008; Ham, 2003; Partida y Tuirán, 2002).

En este sentido, vale la pena estimar cuánto representa la actual emigración de población y fuerza de trabajo de este crecimiento de la población en edades activas y, por ese medio, estimar en forma indirecta la magnitud de lo que representa la virtual exportación del llamado bono demográfico en México. Para hacer estos cálculos usaremos las proyecciones de población total y de población activa elaboradas por el Consejo Nacional de Población (Conapo. Ver Partida, 2008 y 2008b). En estas proyecciones se estima además el volumen de emigración internacional neta para cada año; con base en este dato, podemos estimar la pérdida del bono demográfico como la proporción que representa el flujo neto migratorio en cada año con respecto al incremento de la población activa. Esta estimación nos indica que entre 2007 y 2020, la migración a Estados Unidos representaría una fuga de aproximadamente el 50\% del bono demográfico, esto es, del crecimiento de la población activa. A partir de ese año, en cambio, esta fuga inicia una tendencia ascendente, hasta llegar a representar prácticamente el $100 \%$ en 2030, y continuar creciendo en los siguientes años (ver gráfica 7)

GRÁFICA 7

México, 2007-2035. Migración neta internacional como proporción de la población económicamente activa

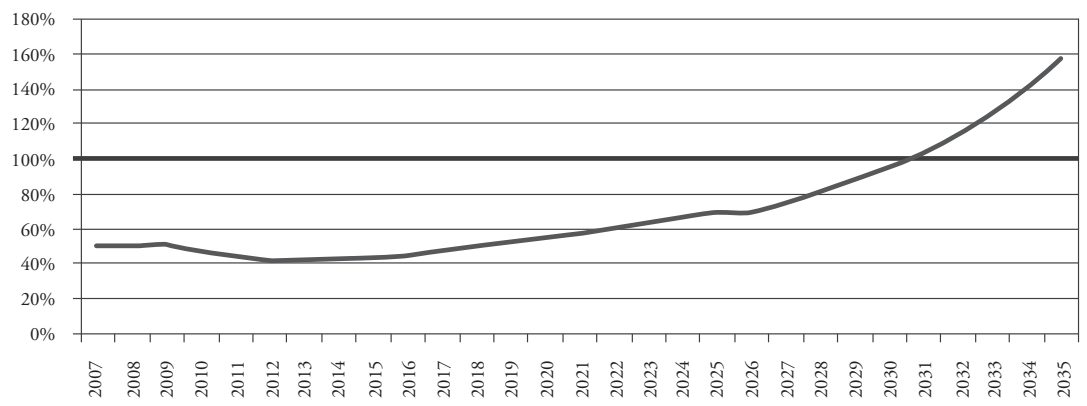

Fuente: Estimaciones propias con base en Partida, 2008a y 2008b.

Se trata, sin duda, de una pérdida significativa no solamente en términos demográficos, sino también de las opciones de crecimiento económico 
que esta población activa podría implicar para México; no se trata de un flujo migratorio pura y simplemente, sino de la pérdida de una ventana de oportunidades que la demografía le presenta a la sociedad mexicana, pero que el modelo de desarrollo no permite capitalizar internamente. En otras palabras, a través de la emigración se estaría transfiriendo a la economía estadounidense gran parte del bono demográfico, permitiendo que en esa economía se concentre el conjunto de beneficios que se derivan de su aprovechamiento y capitalización.

Costos sociales asociados a la emigración: educación y reproducción social

Para los países expulsores de fuerza de trabajo, la migración representa la transferencia de su recurso más preciado: su gente. En este sentido, la emigración no solamente entraña una transferencia del bono demográfico al país receptor, sino que también implica pérdidas en la formación de capital humano. Estas pérdidas se pueden estimar a partir del valor de la inversión social que realiza el país de origen para la formación educativa y la reproducción social de la fuerza de trabajo que emigra.

En la siguiente gráfica, ofrecemos una estimación de los costos educativos y de reproducción social que representó para México la emigración laboral a Estados Unidos entre 1994 y 2008. Para esta estimación hemos usado únicamente los costos de la canasta básica y educación pública, y hemos considerado la edad y el nivel educativo de los migrantes al momento de su llegada a Estados Unidos.

GRÁFICA 8

México: Costo de formación educativa y reproducción social de los emigrantes ocupados que ingresaron a Estados Unidos entre 1994 y 2008

(miles de millones de dólares de 2008)

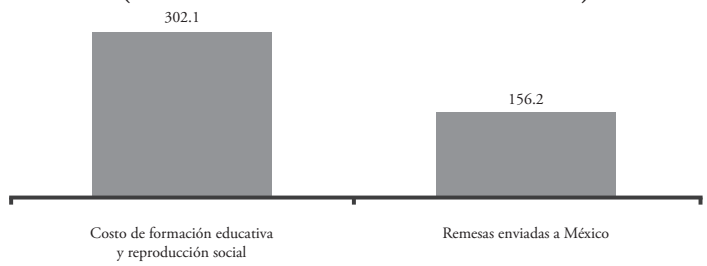

Fuente: Cálculos propios con base en datos de Current Population Survey, 1994-2008, datos de Coneval, Lineas de Pobreza en México y Anuario de Estadísticas Educativas en México, 2008. 
Como puede observarse, mientras los emigrantes laborales representaron para México un costo de 302 mil millones de dólares, esa misma migración solamente generó un volumen de 156 mil millones de dólares, es decir, a través de las remesas, México apenas logra recuperar el 51\% de los recursos usados para sustentar la educación y la reproducción social de esos emigrantes.

Es así que, más que un negocio redondo, donde todos ganan, la migración conlleva una transferencia neta de esta inversión en capital humano y fuerza de trabajo (educación, salud, alimentación, entre otros) hacia Estados Unidos. A estos costos económicos, habría que agregar otras pérdidas, como el desmembramiento de familias, la vulnerabilidad epidemiológica, el despoblamiento, el abandono de actividades productivas, el alcoholismo y la drogadicción, la pobreza, la dependencia de las remesas, entre otros varios problemas sociales (Delgado Wise, Márquez Covarrubias y Rodríguez 2009).

\section{Impactos en los migrantes $y$ sus familias}

En las sociedades de destino, la población migrante suele estar sujeta a condiciones de vulnerabilidad económica y social frente a otros grupos, que se suman a los riesgos que implica el tránsito ante las crecientes medidas restrictivas establecidas por los principales países receptores. Tomando en cuenta lo anterior, en esta sección presentamos algunos indicadores que permiten describir y estimar la condición de precariedad, segregación laboral y exclusión social que afecta preferentemente a los inmigrantes mexicanos en Estados Unidos.

En primer lugar, y considerando los factores implicados en los derechos laborales básicos, en la siguiente gráfica, presentamos un índice de precariedad laboral que pondera la falta de sindicalización, la carencia de seguro médico pagado por el empleador, la ausencia de un plan de pensión o retiro ofrecido por el empleador y la presencia de un trabajo de tiempo parcial.

Como puede observarse, los inmigrantes mexicanos están expuestos a condiciones de mayor precariedad laboral que el resto de la población trabajadora en Estados Unidos. En 2007, el 22\% de los mexicanos 
estaba en condiciones de alta precariedad, esto es, que no disponían de ninguna de aquellas condiciones laborales que configuran un marco de seguridad en el trabajo (sindicalización, seguro médico, plan de pensión, trabajo part time, entre otros), a la vez que otro $27 \%$ estaba en condiciones de precariedad media (tenían sólo una de estas características); solamente el 14\% disponía de todos estos factores que dan cierta seguridad en el trabajo (sindicalización, seguro médico, plan de pensión, y trabajo full time).

En el caso de la población nativa, en cambio, se da la situación inversa. El 40.5\% dispone de todas estas condiciones de protección laboral, mientras que solamente $14.6 \%$ se ubica en condiciones de alta precariedad.

En segundo lugar, una situación que suele estar vinculada a las condiciones de precariedad laboral de los inmigrantes es la segregación ocupacional, que se puede medir con base en la proporción de los trabajadores con altos niveles de cualificación técnica y profesional (educación y preparación escolar) empleados en puestos de trabajo de baja calificación. Al respecto, los datos indican que más de un tercio de los trabajadores mexicanos con altos niveles de educación (estudios técnicos o profesionales) se emplean, sin embargo, en puestos de muy baja calificación (trabajos manuales y servicios no calificados, como servicio doméstico, limpieza y mantenimiento, obreros de la construcción, jornaleros agrícolas, entre otros), mientras que solamente el 9.1\% de los trabajadores nativos con alta educación se emplea en este tipo de trabajos (ver gráfica 9).

GRÁFICA 9

Estados Unidos: Trabajadores según condición de precariedad laboral y segregación ocupacional, 2007

PRECARIEDAD LABORAL

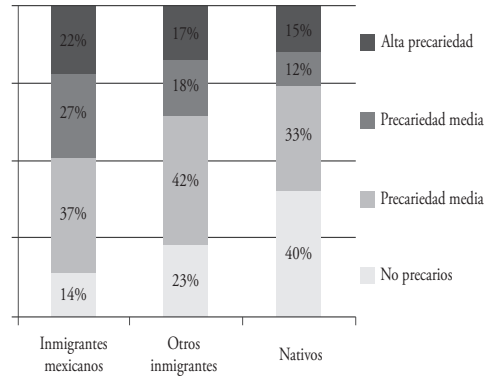

SEGREGACIÓN OCUPACIONAL

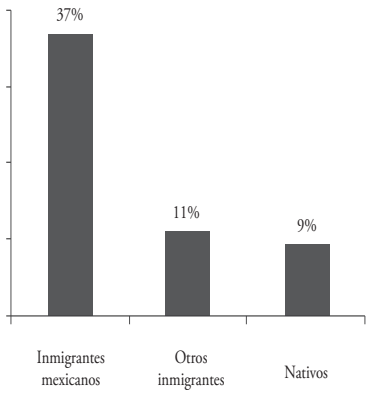

Fuente: Cálculos propios basados en Current Population Survey, march supplement, 2007. 
Finalmente, un tercer indicador que permite dimensionar la gravedad de la situación de vulnerabilidad y exclusión que afecta a los inmigrantes corresponde a la escasa movilidad social intergeneracional, lo cual se refleja en el hecho de que las condiciones socioeconómicas de los inmigrantes mexicanos es muy similar a la de sus descendientes nacidos en Estados Unidos; en efecto, la proporción de inmigrantes mexicanos situados bajo el nivel de pobreza es de $24.2 \%$, proporción que se reduce levemente al 22.1\% entre sus descendientes nacidos en Estados Unidos. En ambos casos, la incidencia de la pobreza es muy superior al promedio nacional. Esto indica que, aunque la situación entre los descendientes mexicanos es ligeramente mejor que la de sus padres inmigrantes, no está implicado un proceso real de movilidad social que los aproxime al promedio nacional (ver gráfica 10).

\section{GRÁFICA 10}

Estados Unidos: Porcentaje de inmigrantes latinoamericanos pobres y sus descendientes, 2007-2008

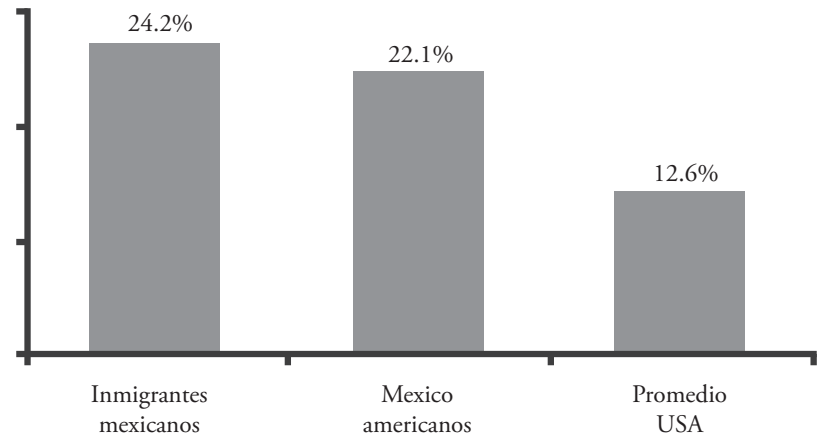

Fuente: Cálculos propios basados en Current Population Survey, march supplement, 2007-2008.

\section{CONCLUSIONES}

Este análisis preliminar del corredor migratorio entre México y Estados Unidos nos señala un escenario que está lejos de ser una situación win-win-win, esto es, en la que todos los actores resultan ganadores (sociedades de origen, de destino y los migrantes mismos). En general, el análisis del balance entre costos y beneficios para los países emisores y receptores, así como para los migrantes y sus familias, muestra una 
situación preocupante, en donde los costos parecen ser mayores que los beneficios para todas las partes involucradas.

En relación con las causas, la evidencia muestra que los actuales modelos de desarrollo tienden a reproducir y, en algunos casos, a acentuar las asimetrías productivas y desigualdades económicas y sociales entre los países emisores y receptores de la migración. En efecto, los modelos de integración económica y comercial han ahondado las diferencias de productividad preexistentes entre México y Estados Unidos. Asimismo, junto a la brecha salarial, la dinámica de los mercados de trabajo en ambos países tiende a complementarse en sus diferencias estructurales. De esta forma, el superávit en fuerza laboral en México tiende a compensar el déficit de fuerza de trabajo que genera el envejecimiento demográfico en Estados Unidos.

El corolario de lo anterior es claro y sugerente. El origen estructural de la migración contemporánea no parece radicar tanto en la las condiciones de pobreza y marginación que prevalecen en los países de origen, como en la prevalencia de un estilo de desarrollo que acentúa las desigualdades sociales y asimetrías económicas entre los países y regiones. En este sentido, la solución no está en la promoción de políticas de desarrollo pura y simplemente, sino en la implementación de otras estrategias y estilos de desarrollo social y económico que combata directamente las desigualdades regionales e internacionales.

En relación con los impactos y contribuciones de la migración en los países de destino, Estados Unidos, en este caso, los indicadores estratégicos que hemos usado nos han permitido ilustrar una serie de beneficios que suele soslayarse en el análisis con los indicadores tradicionales. No cabe duda de que los migrantes hacen contribuciones significativas a la economía de Estados Unidos.

Si el sostenimiento de la economía estadounidense como una economía imperial se sustentaba, en el pasado, en sus propias fuerzas productivas (fuerza de trabajo nativa), hoy, la demografía de ese país no permite la reproducción de la fuerza laboral necesaria para mantener el nivel de desarrollo de las fuerzas productivas del capital, generando un déficit de mano de obra que, de no cubrirse con inmigración, no solamente afectaría el crecimiento económico del país sino, sobre todo, su 
capacidad para mantener el liderazgo político y militar necesario para sustentar sus posiciones imperialistas.

En cuanto a la dinámica demográfica, los indicadores nos muestran la magnitud de la transferencia del bono demográfico mexicano que es capturado por Estados Unidos y que permite compensar los desequilibrios etarios que genera el proceso de envejecimiento de la población nativa. Sin duda, el alto nivel de la migración irregular es un problema serio para la sociedad de acogida; sin embargo, la relación costo/beneficio no parece ser tan negativa como se describe generalmente.

En términos del impacto en los países de origen, México, en este caso, vemos una situación similar, en cuanto a que los indicadores estratégicos que hemos usado nos informan de la debilidad empírica de muchas de las tesis celebratorias de la migración y las remesas.

Por un lado, es claro que el impacto económico de las remesas es ínfimo y que no logra ya no revertir, sino ni siquiera paliar las condiciones estructurales de desigualdad social y estancamiento económico que desde hace dos décadas afectan a la economía mexicana. Por otro lado, cabe señalar los efectos demográficos que están ya manifestándose con la emigración a Estados Unidos. Nos referimos a que, actualmente, con la migración se está transfiriendo más del 50\% del bono demográfico; los beneficios que se obtienen de ello - las remesas-, no logran compensar los costos de reproducción social de esta población que ha emigrado.

Finalmente, para los migrantes y sus familias - dimensión fundamental del análisis, pero que suele estar invisibilizada en los discursos predominantes-, sin duda, la migración representa una opción para escapar de las condiciones de alta marginación que prevalece en sus países de origen; sin embargo, a pesar de que reciben algunos beneficios económicos de la migración, los costos son elevados en la mayoría de las demás dimensiones. En efecto, los migrantes enfrentan situaciones de graves violaciones de los derechos humanos, así como de vulnerabilidad social, tanto en las zonas de tránsito como en los lugares de destino. En particular, cabe señalar las condiciones de precariedad laboral y segregación ocupacional que lleva a muchos migrantes a emplearse en puestos de trabajo que están por debajo de 
sus capacidades. Asimismo, las oportunidades de movilidad social son mínimas y, en general, los niveles de pobreza y exclusión social suelen afectar igualmente a inmigrantes como a sus descendientes nacidos en Estados Unidos.

En síntesis, el análisis de estos indicadores estratégicos en el caso del corredor México-Estados Unidos nos ha permitido iluminar otras dimensiones de la relación migración y desarrollo, que suelen ser soslayadas en los discursos predominantes. De hecho, este análisis nos permite afirmar que los indicadores que tradicionalmente son usados para analizar esta situación terminan distorsionando la realidad y contribuyen más a alimentar una «mitología dominante» subyacente a la construcción social y política del migrante como «enemigo público», alejándose de una visión más integral y comprehensiva, y donde adquiere centralidad la cuestión de los derechos de los migrantes.

Este análisis, aunque exploratorio y muy preliminar, confirma que existe una urgente necesidad de construir y diseñar nuevos indicadores capaces de captar la verdadera naturaleza del fenómeno desde una perspectiva integral, incluyente y más balanceada; ello conducirá, necesariamente, a revertir los términos del debate sobre políticas públicas desplazando el centro de discusión de la agenda de seguridad nacional hacia los ámbitos de desarrollo y derechos humanos de los migrantes. No cabe duda que se necesitan nuevas bases para avanzar en un debate diferente, mejor informado e incluyente, que, sobre todo, incluya una participación más activa de la sociedad civil.

Sin duda, políticas públicas más justas y equitativas requieren nuevos diálogos entre países de origen, tránsito y destino. La iniciativa de los PM ha sido un avance importante; sin embargo, planteamos la necesidad de ampliar sus alcances, considerando los corredores como unidades analíticas, y construyendo un conjunto de indicadores estratégicos que sirvan de herramienta para un análisis comprehensivo de las causas y consecuencias de la migración en cada corredor. Asimismo, se requiere una caracterización más exhaustiva de los vínculos entre la migración y el desarrollo, junto a una revisión de los impactos, incluyendo no solamente económicos y demográficos, sino también en los de las situaciones sociales, culturales y políticas de los migrantes 
mismos. Finalmente, un enfoque de este tipo debe ser capaz de introducir el tema de los derechos humanos en el debate, junto a una serie de propuestas específicas para la acción.

En este documento hemos querido plantear diversas ideas y propuestas en esa dirección, señalando, entre otros aspectos, los principios que deberían distinguir el nuevo sistema de manejo de la información, y las característica de los indicadores que se necesitan para las varias dimensiones del análisis.

\section{BIBLIOGRAFÍA}

AGP (Acción Global de los Pueblos sobre Migración, Desarrollo y Derechos Humanos) (2010), Pronunciamiento de la Acción Global de los Pueblos sobre Migración, Desarrollo y Derechos Humanos. Ciudad de México, 2-5 Noviembre de 2010, http://www.accionglobalmexico.org/doc/AGP-pronunciamiento.pdf

(2010) IV Foro Global, noviembre, México, http://www.accionglobalmexico.org/doc/AGPfinal/1-SI-Puentes-Canales-etal-29-102010.doc

CANALES, Alejandro I. (2011), «Las profundas contribuciones de la migración latinoamericana a los Estados Unidos». En Jorge Martínez Pizarro (ed.) Migración internacional en América Latina y el Caribe. Nuevas tendencias, nuevos enfoques. CEPAL, LC/R.2170 Santiago de Chile (pp. 257-331).

(2009), «Migración internacional y desarrollo. Evidencias del aporte de los mexicanos a la economía de Estados Unidos». En Paula Leite y Silvia E. Giorguli (Coordinadoras) El estado de la migración. Las políticas públicas ante los retos de la migración mexicana a Estados Unidos. Consejo Nacional de Población, México.

(2008), Vivir del norte. Remesas, desarrollo y pobreza en México. Consejo Nacional de Población, México.

Canales, Alejandro y Ruben Puentes (2010), Indicadores Estratégicos: sistemas de información e indicadores para desmitificar la relación entre migración y desarrollo. Presentación en la Conferencia de la AGP, noviembre, México.

Canales, Alejandro I. e Israel Montiel Armas (2004), «Remesas e inversión productiva en comunidades de alta migración. El caso de Teocaltiche, Jalisco». Migraciones Internacionales, vol. 2, núm. 3, enero-junio, pp. 142-172. El Colegio de la Frontera, México. 
Citron Laura y Richard Gowan (2004), European Civic Citizenship and Inclusion Index. British Council Foreign Policy Centre and Migration Policy Group. Brussels.

Сммі (Comisión Mundial sobre las Migraciones Internacionales) (2005), Las migraciones en un mundo interdependiente: Nuevas orientaciones para actuar, http://www.gcim.org/mm/File/Spanish(1).pdf

conapo (2008), Informe de México: El cambio demográfico, el envejecimiento y la migración internacional en México. Consejo Nacional de Población. Trabajo presentado en la reunión del Comité Especial sobre Población y Desarrollo, XXXII Periodo de Sesiones de la Comisión Económica para América Latina y el Caribe. Santo Domingo, República Dominicana.

Delgado Wise, Raúl, Humberto Márquez y Ruben Puentes (2010), Elementos para Replantear el Debate sobre Migración, Desarrollo y Derechos Humanos. Acción Global de los Pueblos para la Migración, Desarrollo, y los Derechos Humanos (AGP). IV Foro Global. Noviembre 2010, México, http://www.accionglobalmexico.org/doc/AGPfinal/0-ESP-Delgado-Marquez-Puente-22102010.pdf

Delgado Wise, Raúl y Humberto Márquez (2009), «Understanding the Relationship between Migration and Development: Toward a New Theoretical Approach», Social Analysis, vol. 53, núm. 3 (pp. 85-105).

(2007), «El sistema migratorio México-Estados Unidos: dilemas de la integración regional, el desarrollo y la migración». En S. Castles y R. Delgado Wise (coords.) Migración y desarrollo: perspectivas desde el sur, Miguel Ángel Porrúa/ Universidad Autónoma de Zacatecas, México.

Delgado Wise, Raúl, Humberto Márquez Covarrubias y Héctor Rodríguez (2009), "Seis tesis para desmitificar el nexo entre migración y desarrollo", Migración y Desarrollo, número 12, primer semestre de 2009.

GFMD (Global Forum on Migration and Development) (2010), Information Note on Migration Profiles. Ad Hoc Working Group on Policy, Coherence, Data and Research. Drafted by Iом in conjunction with the Working Group coordinator, Puerto Vallarta.

(2011), Taking Action on Migration and Development - Coherence, Capacity and Cooperation. Concept Paper. Global Forum on Migration and Development; Switzerland 2011. Disponible en: http://www. unitar.org/ny/sites/unitar.org.ny/files/Swiss\%20GFMD\%20Concept\%20 Paper_04march2011\%5B1\%5D.pdf 
Ham, Roberto (2003), El envejecimiento en México: el siguiente reto de la transición demográfica. El Colegio de la Frontera Norte/ Miguel Ángel Porrúa, México.

Harttgen, Kenneth y Stephan Klasen (2009), A Human Development Index by Internal Migrational Status. Courant Research Centre, Georg-August-Universität Göttingen, Discussion Paper, núm. 5.

Has, Hein de (2007), Remittances, Migration and Social Development. $\mathcal{A}$ Conceptual Review of the Literature. United Nations, Research Institute for Social Development, Social Policy and Development Programme Paper Number 34.

Kapur, Devesh (2004), Remittances: The New Development Mantra?. Naciones Unidas, G-24 Discussion Paper Series.

Laczko, Frank (2011), Migration Profiles: Concept and IOM Experience. Research and Publication Division, http://www.euromed-migration.eu/ e1152/e3411/e3427/e4025/e4053/pres, Genève.

Manzelli, H. (2011), «Migration profiles: Developing evidence-base migration and development policies». Presented at GFMD meeting in New York, 30 de junio.

MPG (Migration Policy Group) (2011), Migration Integration Policy Index (MIPEX), http://www.mipex.eu/

Martínez Pizarro, Jorge (2008) América Latina y el Caribe: migración internacional, derechos humanos y desarrollo. Comisión Económica para América Latina y el Caribe. Serie Libros de la CEPAL, núm. 97, Santiago de Chile. oNu (Organización de las Naciones Unidas) (1998), Recommendations on Statistics of International Migration. Statistical Papers Series M, núm. 58, rev. 1, New York.

Partida, Virgilio (2008), Proyecciones de la población de México, 2005-2050, Consejo Nacional de Población, México.

(2008b), Proyecciones de la población económicamente activa de México y de las entidades federativas, 2005-2050, Consejo Nacional de Población, México.

PARTIDA, Virgilio y Rodolfo Tuirán (2002), «Evolución futura de la población mexicana: envejecimiento y bono demográfico», en Brígida García Guzmán (coord.), Población y sociedad al inicio del siglo XXI, El Colegio de México, México (pp. 25-53). 
Puentes, Ruben, Alejandro Canales, Héctor Rodríguez, Raúl Delgado Wise y Stephen Castles (2011), Towards an assessment of migration, development and human rights links: Conceptual framework and new strategic indicators. SAnto Tomas, Patricia A., Lawrence H. Summers y Michael Clemens (2009), Migrants Count: Five steps toward better migration data. Center for Global Development. Report of the Commission on International Migration Data for Development Research and Policy, Washington. 
